\title{
Ultrafast display buildup with standard VGA on MS-DOS computers
}

\author{
INGO SPITCZOK VON BRISINSKI \\ Free University of Berlin, Germany
}

\begin{abstract}
Tachistoscopic examinations, determinations of reaction times after visual stimuli, and latency measurements of visual evoked potentials require well-defined and often very fast display buildup on the monitor. Display buildup takes at least $14 \mathrm{msec}$ when a VGA board is used in standard video modes. This time can be reduced to $4 \mathrm{msec}$ or less by reprogramming some registers of the display adapter.
\end{abstract}

Precise presentation of visual stimuli is a prerequisite for most psychological and physiological examinations. A precision of $1 \mathrm{msec}$ is required for measuring reaction times, which rarely exceed $1.5 \mathrm{sec}$ (Brysbaert, Bovens, d'Ydewalle, \& van Calster, 1989). High precision also appears to be important for determining latencies of visual evoked potentials (VEP), which may range between $75 \mathrm{msec}$ (VEP) and 1,000 msec (event-related potentials; Stöhr, Dichgans, Diener, \& Buettner, 1989).

\section{Standard Graphic Modes on MS-DOS Computers Are Slow}

The speed of display scan on the monitor is primarily determined by the display adapter of the computer and the monitor. VGA (video graphic array) has become the accepted standard on MS-DOS computers. The (preset) standard video modes of VGA allow for maximum vertical frequencies of $70 \mathrm{~Hz}$, which corresponds to a scan time of approximately $14 \mathrm{msec}$. About $1 \mathrm{msec}$ can be deducted from this value for the (invisible) vertical retrace of the cathode ray. Even the Super VGA (SVGA) boards now available rarely achieve vertical frequencies higher than about $90 \mathrm{~Hz}$. Thus, the maximum time interval between the beginning of the time measurement and the actual start of the display scan is $14 \mathrm{msec}$ at a vertical frequency of $70 \mathrm{~Hz}$.

\section{Reprogramming of the VGA Accelerates Display Buildup}

The display is composed of lines, which, in the standard video modes, consist of 640 (graphic modes) or 720 (text modes) visible pixels (Michael, 1988) with invisible pixels at the left and right margin (horizontal overscan). In graphic modes with 256 colors, every pixel is visual-

Correspondence should be addressed to the author at Abteilung für Psychiatrie und Neurologie, des Kindes- und Jugendalters, Universitätsklinikum Rudolf Virchow, Standort Charlottenburg, Freie Universität Berlin, Platanenallee 23, D-14050 Berlin, Germany. ized twice (double-scanning), hence the actual horizontal resolution available is only 320 pixels (Michael, 1988).

Depending on the video mode, a screen consists of 350 , 480 , or 400 visible lines. At a resolution of 200 lines, each line is again displayed twice, and there are also some invisible lines at the upper and lower margins (their number depends on the video mode).

The speed at which pixels are displayed on the screen is determined by the frequency of the timing generator, which is set at $25 \mathrm{MHz}$ at a 640-pixel resolution and at $28 \mathrm{MHz}$ at a 720 -pixel resolution. Other timing frequencies are not available for a standard VGA.

The fewer lines displayed per screen, the faster the display buildup. For example, a video mode with a resolution of $640 \times 480$ pixels is displayed at a repetition frequency of only $60 \mathrm{~Hz}$, as opposed to $70 \mathrm{~Hz}$ for a resolution of $640 \times 350$ pixels (Spitczok von Brisinski, 1991a). Since the standard video modes are not designed for fewer than 350 lines per screen (remember that $\mathbf{4 0 0}$ lines are displayed physically at a resolution of 200 lines), the maximum display repetition frequency is $70 \mathrm{~Hz}$. Different resolutions can be achieved by reprogramming the cathode ray tube controller (CRTC) (Spitczok von Brisinski, 1991b, 1992a, 1992b). The repetition frequency can be increased by reducing the number of physically displayed lines.

The software routines developed by the author yield repetition frequencies of up to $289 \mathrm{~Hz}$, reducing the time of display buildup to less than $4 \mathrm{msec}$. The velocities were measured by using the program VTiming (Gerdes, 1991), which registers the time interval between two successive vertical cathode ray retracings by means of the PC timer component. In addition, the velocities were determined by an oscilloscope connected to the video port of the PC. The two procedures yielded identical values.

The program contains register values for 20 different vertical resolutions ranging from 363 to 101 pixels. All resolutions can be used for the 2-, 16-, and 256-color display, and it is possible to fill two different "pages" in each case. When the 256-color mode is used, horizontal resolution is only 320 rather than 640 pixels due to the required double-scanning. 
Other vertical resolutions can be achieved by assigning appropriate values to the CRTC registers 06h (vertical total register), 07h (CRT, controller overflow register), 09h (maximum scan line register), 10h (vertical retrace start register), $11 \mathrm{~h}$ (vertical retrace end register), $12 \mathrm{~h}$ (vertical display enable end register), $15 \mathrm{~h}$ (start vertical blanking register), and $16 \mathrm{~h}$ (end vertical blanking register) (Ferraro, 1990; Michael, 1988). At vertical resolutions between 101 and 255 pixels, 1 is subtracted from Ymax before the latter is assigned to registers $10 \mathrm{~h}$ and $12 \mathrm{~h}$; for register $06 \mathrm{~h}$, a value between 6 and 12 is added (physically required overscan; the value should be as low as possible for high velocities, and distortion at the margins should be kept at a minimum). Only Bit 4 is set in register 07h (line compare). Different combinations of values can be used for vertical blanking. The following combination has proved useful: Bit 5 in register $09 \mathrm{~h}$ (start vertical blanking), a value of 4-6 in register $16 \mathrm{~h}, 136$ or 231 in register $15 \mathrm{~h}$, and 230 in register $11 \mathrm{~h}$.

At vertical resolutions between 256 and 511 pixels, 257 (the sum of -256 and -1 ) is subtracted from Ymax before the latter is assigned to registers $10 \mathrm{~h}$ and $12 \mathrm{~h}$; for register $06 \mathrm{~h}$, a value of 12 is added. In overflow register 07, Bits 0-4 have to be set (the individual bits represent the 8th bit, and thus a value of 256 , for registers $06 \mathrm{~h}$, $12 \mathrm{~h}, 10 \mathrm{~h}, 15 \mathrm{~h}$, and line compare, respectively). For vertical blanking, the following values have proved useful: Bit 6 in register 09h (line compare) in combination with a value of 86-108 in register $16 \mathrm{~h}$ and, in register $15 \mathrm{~h}$, a value lower by one than that in register $16 \mathrm{~h}$, and a value between 202 and 206 in register $11 \mathrm{~h}$.

\section{Selection of a Suitable Monitor}

Surprisingly, the best results have been achieved with inexpensive standard VGA fixed-frequency monitors, both monochrome and color. As indicated above, the horizontal frequency is standardized and set at approximately $31.5 \mathrm{kHz}$. As with display adapters, many VGA fixedfrequency monitors (e.g., Commodore 1403) also have a variable vertical frequency. Thus, about 100 horizontal lines can be displayed on these monitors at $289 \mathrm{~Hz}$ (cf. above). When using such monitors, the cathode ray scans only about one quarter of the available screen, since the distance between the horizontal lines is not changed. There are also fixed-frequency VGA monitors on the market with two fixed vertical frequencies $(60$ and $70 \mathrm{~Hz}$; e.g., Commodore 1944). These monitors cannot be used at higher frequencies.

So-called multiscan monitors, which "automatically" adjust to the required (vertical and horizontal) frequencies, can also be used with the increased vertical frequencies of a standard VGA or a VGA-register-compatible SVGA. However, since multiscan monitors are not standardized, the results may vary widely. All multiscan monitors can be operated at a somewhat higher vertical frequency than is specified in the technical data. For instance, the Eizo 9070 s, which has a specified maximum frequency of $80 \mathrm{~Hz}$, can be operated at $143 \mathrm{~Hz}$ with a vertical resolution of 210 instead of 400 dots. Higher vertical frequencies do not provide a correct image. This is not due to an "overload" of the monitor but simply to the fact that it is not designed to synchronize at higher values. A number of multiscan monitors also display 100 lines at $289 \mathrm{~Hz}$ without problems (e.g., Eizo 9400). Unlike the singlefrequency monitors, all multiscan monitors space out the lines displayed - that is, they distribute the 100 lines over the entire screen.

\section{Software Specifications}

FASTVGA is a collection of routines written in $\mathrm{C}$ and Turbo Pascal that can be incorporated into other programs to speed up display scan. The program can be used for monochrome and color display. Hardware requirements are an IBM-compatible MS-DOS computer (XT; 286, 386 , or $486 \mathrm{AT}$ ) operated with MS-DOS version 3.3 or higher and a VGA or register-compatible SVGA (the program does not operate with other display adapters such as CGA or EGA). Any monitor can be used subject to the above-mentioned restrictions. The software was tested extensively; none of the monitors tested was overloaded or damaged.

\section{Availability}

The source code can be obtained free of charge from the author by sending a formatted diskette (double or high density; 3.5 in. or 5.25 in.).

\section{REFERENCES}

Brysbaert, M., Bovens, N., D'Ydewalle, G., \& van Calster, J. (1989). Turbo Pascal timing routines for the IBM microcomputer familiy. Behavior Research Methods, Instruments, \& Computers, 21, 73-83.

FerRaro, R. F. (1990). Programmer's guide to the EGA and VGA cards. New York: Addison-Wesley.

Gerdes, M. (1991). Messung der VGA-Bildablenkfrequenz per Software [Measurement of the VGA-display repetition frequency by software]. Magazin für Computer Technik (c't), 7, 188-193.

MichaEL, M. (1988). VGA-Kompendium [VGA Compendium]. Haar: Markt \& Technik Verlag.

SPITCZOK VON BRISINSK, I. (1991a). EGA mit $70 \mathrm{~Hz}$ [EGA with $70 \mathrm{~Hz}$ ]. Magazin für Computer Technik (c't), 6, 8.

SPITczoK vON BRISINSKI, I. (1991b). Selbstgestrickt-neue Grafik-Modi auf der Standard-VGA [Self-knitted-new graphic modes on standard VGA]. Magazin für Computer Technik (c't), 12, 212-216.

SPITCZOK VON BRISINSKI, I. (1992a). Schräge Typen-Texte auf der VGA in beliebigen Winkeln oder Kreisen ausgeben [Oblique types-text display on VGA at any angle or circle]. Magazin für Computer Technik (c't), 11, 182-187.

SpItczok von Brisinski, I. (1992b). Zwei Seiten mit 256 KB [Two pages with $256 \mathrm{~KB}$ ]. CHIP, 9, 301.

Stöhr, M., Dichgans, J., Diener, H. C., \& Buettner, U. W. (1989). Evozierte Potentiale. Berlin: Springer-Verlag.

(Manuscript received July 8, 1991; revision accepted for publication August 19, 1993.) 